\title{
Analysis of occupational injuries in the sea fishing industry according to the type of fishery and the fishing activity
}

\author{
Christine Chauvin, Gilbert Le Bouar, Salim Lardjane
}

Université Bretagne Sud, Lorient, France

\begin{abstract}
Background: Sea fishing is one of the most dangerous occupations. Numerous studies have already sought to evaluate the risk level of this occupation through the analysis of the frequency and seriousness of occupational injuries. The purpose of the present study is to analyse these accidents in terms of two main characteristics of the vessels involved: the fishery type (high seas, offshore, coastal, or inshore fishery) and the fishing activity (use of passive or active gears).

Materials and methods: Injury rates were calculated for the Brittany region and for the year 2012. A second analysis was carried out on 8,286 reported injuries that occurred in France from 2002 to 2012, while vessels were in the process of fishing.

Results: This first analysis shows that the incidence rate is very high (103 per 1,000 full-time equivalent fishermen) and that it depends more on the fishery type than on the fishing activity; the highest rates concern the offshore and the coastal fleets. Results of the second analysis show that the nature of accidents depends more on the fishing activity than on the type of fishery.

Conclusions: These findings lead to a discussion of the causes of the highest incidence rate values and the causes of the observed variations. The discussion also involves the methodological difficulties related to the incidence rate calculations.
\end{abstract}

(Int Marit Health 2017; 68, 1: 31-38)

Key words: fishing fleet, fishery, occupational injuries, incidence rates

\section{INTRODUCTION}

The sea fishing industry shows unique features. In Western countries, it is one of the last gathering activities. Strongly regulated, it depends on the state of the fish stocks and of the aquatic environment. It must adapt to the various measures aiming at managing the sustainable use of fishery resources. It is mainly a craft activity. In France, small-scale fishing concerns 'every fishing vessel less than $24 \mathrm{~m}$ long with the owner on board', and 95\% of the French fishing fleet is made up of vessels less than $25 \mathrm{~m}$ long.

In this sector, numerous regulations related to vessel safety and to work safety have been implemented over the last few years. However, despite positive trends [1], sea fishing remains one of the most dangerous and hardest occupations. In Europe, the mean ratio of acci- dent-caused deaths per 10,000 fishermen is between 8.71 and 11 [2-6], but can be far more important for certain segments of the fleet; in Norway, the factor of 24.8 fatal accidents per 10,000 man years was found in the smaller fleet for the period 1998-2006 [7]. It is well above the values that characterise land-based industries, ranging between 1.5 and 4 for 10,000 workers for northern Europe countries [8].

Commercial fishing is dangerous, but it encompasses many different situations depending upon the vessel length, the gear used to catch the fish, and the fishery type. The study presented in this paper addresses the following question: Does the accidentology depend upon the fishing gear used by the fishing vessels (i.e., the fishing activity) and/ /or the type of fishery? With regard to the fishing gears, the 
Table 1. Fishery categories in France

\begin{tabular}{ll}
\hline Types of fishery & Definition \\
\hline High seas fishery & $\begin{array}{l}\text { Vessels over 1,000 GRT or vessels over } \\
150 \text { GRT if out of port }>20 \text { days }\end{array}$ \\
$\begin{array}{ll}\text { Offshore fishery } & \text { Out of port }>96 \mathrm{~h} \\
\text { Coastal fishery } & 24 \mathrm{~h}<\text { out of port } \leq 96 \mathrm{~h} \\
\text { Inshore fishery } & \text { Out of port } \leq 24 \mathrm{~h}\end{array}$ \\
GRT - gross register tonnage
\end{tabular}

study includes trawl nets, dredges, seine nets, net, pots, and lines. These fall under two general categories:

- towed gears, also known as active or mobile gears (such as trawl nets or dredges). Towed gear is towed through the water, either on or off the seabed, to overrun the target species or herd the fish into the net.

- passive gears, which are left in place for a period before retrieval (such as nets, pots, seine nets, lines, longlines).

In France, four types of fishery are identified in terms of the duration of each absence from port and the vessel's tonnage (Table 1). The type of fishery constitutes a variable that is partially conflated with vessel length.

- High seas fishery, involving vessels over 1000 gross register tonnage (GRT) (or vessels over 150 GRT if they go out of port more than 20 days), is made up of trawlers, tuna vessels, and longliners between 60 and $80 \mathrm{~m}$ long, where the crew may include as many as 50 fishermen.

- Offshore fishery involves vessels going out of port more than $96 \mathrm{~h}$. They are trawlers above $38 \mathrm{~m}$ long (with 10 to 14 fishermen), mid-shore trawlers from 25 to $38 \mathrm{~m}$ long (with 6 to 9 fishermen), or vessels from 16 to $25 \mathrm{~m}$ long (with 5 or 6 fishermen on board). These vessels leave port for a period of 10 days on average. After capture, the fish are frozen or placed on ice.

- Coastal fishery involves vessels whose length does not exceed $20 \mathrm{~m}$ and that go out for periods of 24-96 $\mathrm{h}$. During these trips, the crew (4 fishermen on average) empties, cleans, and places the fish on ice.

- Inshore fishing is conducted along the coastlines, on small vessels of less than $16 \mathrm{~m}$ long and often fewer than $12 \mathrm{~m}$ in length. The landed fish is fresh. The crew is composed of two fishermen on average.

The purpose of the present study is to analyse occupational accidents in the sea fishing industry according to the two main characteristics of the vessels involved: the fishery type (high seas, offshore, coastal, or inshore fishery) and the fishing activity (use of passive or active gears).

\section{MATERIALS AND METHODS}

The analysis of occupational injuries is based on the calculation of the incidence rate, which is the number of accidents divided by the number of people employed in a given sector and during a given time period. This indicator has been used in various studies dealing with occupational injuries in the sea fishing industry, whether fatal or not. In this sector, the denominator definition (the number of people used in the calculation) is highly relevant because many fishermen do not work full time or are seasonally employed. It is therefore necessary to calculate a full-time equivalent (FTE) workforce number [9]. The FTE is defined as the ratio of the total number of paid hours during a period by the number of working hours in that period. In other words, one FTE is equivalent to one employee working full-time.

The present study relies on two types of data: i) data related to occupational injuries that occurred in the French sea fishing industry and were reported between 2002 and 2012, and ii) data on employment in this sector that enable the calculation of the FTE workforce per type of fishery and type of vessels.

\section{OCCUPATIONAL INJURIES DATA}

In France, as in many other countries, it is mandatory to declare any maritime occupational injury (MOI). The employer must establish a detailed report, to which will be attached a form describing the circumstances of the $\mathrm{MOI}$ (CMOI), filled in by the master or the employer. Those documents are handed over to the State Department responsible for maritime issues, checked, supplemented, and then passed on to the relevant healthcare insurance office.

The present study is based on the analysis of the data contained in the $\mathrm{CMOI}$ forms. They are related to:

- the injured person (identity, position, age);

- the main features of the ship (registration, fishery type, length, fishing gear used at the time of accident);

- the circumstances of the injury (date, local time of accident, meteorological conditions, activity of the seafarer at the time of the accident, location of accident, position of the vessel);

- the injury itself (causes of accident, nature of injury, injured body part, consequences).

A database of 14,058 forms was established from the CMOI forms collected between 2002 and 2012. Forms concerning shellfish breeding and diving were excluded.

\section{DATA ON EMPLOYMENT IN THE FRENCH SEA FISHING INDUSTRY}

The key figures given to characterise the sector of the sea fishing industry in France are those of 20,000 fishermen embarked on 5,000 fishing vessels. Each year, the observatory of prospective trends in fishing occupation and qualification establishes a full picture of employment in this sector. It provides the breakdown of fishermen by region and by fishery type but also by duration of the period spent 
Table 2. Fishing vessels, fishermen, maritime occupational injury (MOI) and incidence rate (IR) in Brittany (2012)

\begin{tabular}{lllllll}
\hline Fishery type & High seas & Offshore & Coastal & Inshore & NR & Total \\
\hline Number of vessels & 18 & 143 & 127 & 969 & 1257 \\
Number of fishermen & 394 & 1378 & 712 & 2169 & 4653 \\
Paid days & 117,000 & 345,142 & 181,064 & 546,644 & $1,189,850$ \\
Number of fishermen in FTE & 325 & 959 & 503 & 1,518 & 3,305 \\
Average number of fishermen (FTE)/vessel & 18 & 7 & 4 & $1-2$ & & 341 \\
Number of MOls with sick leave & 13 & 126 & 78 & 116 & 8 & 103.17 \\
IR & 40 & 130.34 & 155 & 77 & &
\end{tabular}

FTE - full-time equivalent; NR - non response

on board and by position occupied on board [10]. From the source data, it is also possible to know the workforce numbers and the number of days of work according to the district in which the fishermen are registered, the type of vessel, and the fishery type.

\section{DATA ANALYSIS}

\section{Calculation of the incidence rate}

The available data on occupational accidents and employment in the sea fishing industry enable the calculation of an incidence rate (IR) taking into account a full-time equivalent (FTE) workforce. In this case: IR = (number of accidents)/FTE $\times 1000$, where FTE $=$ number of days of work/360 (In the maritime administration, 1 year is made up of 360 days (12 months $\times 30$ days per month).

The IR may be calculated per fishery type, since this information is contained in the $\mathrm{CMO}$ forms and since the number of days worked is also known for each type of fishery. In contrast, the employment data are not given per fishing activity (type of gear used); they are available per type of vessel. It was therefore necessary to "translate" the information "type of vessel" in terms of "fishing activity". This process required the use of a vessel database indicating, for each vessel registered in a given district, the vessel's type and its primary and its secondary fishing gear. Performed manually and for each vessel, this task was carried out only for the Brittany region and for 2012. This region was selected because it employs $30 \%$ of the French fishermen.

\section{Identification of the $\mathrm{MOI}$ features according to the fishery type and the fishing activity}

Besides the IR calculation, the CMOI database for the period 2002-2012 was used to identify the features of the occupational injuries that could be specific to certain types of fishery or to certain fishing activities. Bivariate analyses were used to explore dependencies between different modalities of variables considered in pairs. Chi-square testing established the significance of the relationships.

\section{INCIDENCE RATE}

\section{RESULTS}

In 2012, there were in Brittany 1,257 fishing vessels and 4,653 fishermen (excluding those involved in oyster farming, aquaculture, "special fishing", and seaweed harvesting) totalling $1,189,850$ days of "navigation". The days of so-called navigation involve days spent on board French ships, days of sick leave, days of rest, and paid time off. Hence, these are not days of sailing per se, but paid days. For the same year, 499 occupational injuries were recorded, 341 of which were followed by a period of sick leave. Table 2 shows the breakdown of vessels, fishermen, paid days, and FTE per fishery type. These data were used to calculate an overall incidence rate and an incidence rate according to the fishery type.

For each fishery type, the IR was calculated according to the fishing activities (use of active or passive gear). As explained in Section "Calculation of the incidence rate", preliminary processing was necessary to identify the fishing activity of vessels. It revealed that high seas fisheries are specialised in one kind of activity and that versatility is minimal for offshore and coastal fisheries. Among the 143 offshore fishing vessels, 120 are geared up only on trawl ( $78 \%$ of the total number), 3 use Danish seine which may be considered either as a passive gear or as an active one and $18(12.6 \%)$ use only passive gears (nets and/or pots or lines). Only 2 vessels are not typical ones (using pots and trawl for one of them, trawl and nets for the other one). They have been classified according to their main gear. One third of coastal fishing vessels used several gears, but within a main category (either active or passive gear). In Brittany, and in 2012, 127 vessels were practicing coastal fishing. Seventy-seven used only active gears (trawl only or trawl and dredge), 44 used only passive gears (nets and/or pots and/or lines). Six vessels used both gears: 3 trawlers used also the line as a secondary gear, 1 trawler used also nets and 2 vessels used dredge and nets or seine. A weighting coefficient has been assigned to these vessels (and to their crew), in order to take into account the amount of 
Table 3. Incidence rate (IR) according to the fishery type and the fishing activity, for Brittany, 2012 (When the vessel gear was not specified, the injury was not taken into account in the IR calculation)

\begin{tabular}{|c|c|c|c|c|c|c|c|c|c|}
\hline \multirow[t]{2}{*}{ Gear } & \multicolumn{2}{|c|}{ High seas } & \multicolumn{2}{|l|}{ Offshore } & \multicolumn{2}{|l|}{ Coastal } & \multicolumn{3}{|l|}{ Inshore } \\
\hline & Active & Passive & Active & Passive & Active & Passive & Active & Passive & Multi-purpose \\
\hline Number of vessels & 2 & 16 & 121 & 19 & 80 & 47 & 213 & 558 & 196 \\
\hline Number of fishermen & 106 & 288 & 1169 & 174 & 415 & 297 & 477 & 1249 & 439 \\
\hline Paid days & 31,160 & 85,840 & 294,373 & 42,593 & 106,403 & 74,661 & 120,152 & 314,812 & 110,586 \\
\hline FTE & 87 & 238 & 818 & 118 & 296 & 207 & 334 & 874 & 307 \\
\hline Average FTE/vessel & 43 & 15 & $6-7$ & 6 & 4 & & & $1-2$ & \\
\hline $\begin{array}{l}\text { Number of MOls with } \\
\text { sick leave }\end{array}$ & 3 & 8 & 110 & 14 & 45 & 31 & 37 & 52 & 21 \\
\hline IR & 34.5 & 33.6 & 134.47 & 118.64 & 152 & 150 & 110.8 & 59.5 & 68.4 \\
\hline
\end{tabular}

$\mathrm{MOI}$ - maritime occupational injury; FTE - full-time equivalent

time devoted to the main gear (coefficient of 0.6) and to the secondary one (coefficient of 0.4). These coefficients are arbitrary; nevertheless, professionals have considered them as plausible.

In contrast, versatility is widespread in inshore fishery (62\% of vessels).

This preliminary processing enabled us to distribute the seafaring workforce working in high seas, offshore, and coastal fisheries into two main categories of vessels: those using active gear and the other passive gear. This distribution could not be carried out for inshore fisheries because of the number of multipurpose vessels; for those fisheries, a third category was added for the multipurpose vessels.

Table 3 shows that IRs calculated for both fishing activities are comparable in high seas fishery as in coastal fishery. In offshore fishery, the IR calculated for the active gears (trawls) is greater than the IR calculated for the passive ones (nets and/or pots or lines). The Danish seine doesn't appear in Table 3, since no MOls occurred on board the 3 vessels practicing this fishing activity.

Inshore fishery presents singular features compared to the other kinds of fishery. Most of the small vessels use passive gears and the IR, for these vessels, is relatively low (59.5) whereas the mean IR for all fisheries is 103. In contrast, small vessels using active gears experience more accidents than others; for these vessels, the IR is superior to the mean IR (110.8 compared to 103). A large majority of these 213 (71\%) vessels use trawl as main gear and dredge as secondary gear. Most of the accidents (65\%) also occur during trawling activities.

\section{Discussion}

These first analyses, dealing with incidence rates, indicate a mean IR of 103 , which is very high. It is similar to the rate of 107 calculated for the French fishing industry [11]. In contrast, it is much higher than the rate of 92 (for 10,000) calculated for the Norwegian fishery (period 2008-2011) [9].
This rate cannot be compared to IRs that are computed for onshore occupations, because in France, those include the real rather than the FTE number of workers.

These analyses reveal large differences of IR according to the fishery type: occupational injuries are more frequent in the offshore and coastal fisheries than in inshore fishery and even more so when compared to high sea fishery. An additional data item confirms this statement: the vessels between $16 \mathrm{~m}$ and $25 \mathrm{~m}$ long generated 39\% of occupational injuries in 2012 whereas they accounted for $13 \%$ only of the Breton fishing vessels. For high seas and coastal fisheries, there is no difference between the use of active and passive gears. There is a small difference in favour of passive gears in offshore fishery and a very important one in inshore fishery.

\section{MAIN FEATURES OF OCCUPATIONAL INJURIES}

The purpose of this section is to provide an answer to the following question: Do the different types of fishery and the different fishing activities generate specific accidents, showing special features, in terms of circumstances (sailing conditions, activity of the wounded fishermen at the time of the accident), type of accident, causes (the physical element involved), and consequences (physical damage, location of injury)? Analyses carried out in order to answer this question were based on the $\mathrm{CMO}$ I forms collected between 2002 and 2012. A database of 14,058 forms was built. For the purpose of this article, we present the analysis of the 8,286 occupational injuries that occurred during fishing operations. They represent 59\% of the injuries; the others occurred when the vessel was underway $(9 \%)$ or in dock (28\%). A previous study dealt with dockside accidents [12].

\section{Sailing conditions}

Although occupational injuries occur mainly (53.59\%) in good weather conditions, there are disparities according 
Table 4. Percentage of occupational injuries for each macro-category of tasks

\begin{tabular}{lll}
\hline CMOI list of tasks & Groups of tasks & MOI [\%] \\
\hline Preparing fishing gear, shooting fishing gear, hauling fishing gear & Operations related to the fishing gear (A) & $52 \%$ \\
Catch processing and handling & Catch processing and handling & $31 \%$ \\
$\begin{array}{l}\text { Bridge watch keeping, engine room watch keeping, galley duties, } \\
\text { maintenance work, berthing or casting off, embarking and disembarking }\end{array}$ & Additional tasks & $10 \%$ \\
Resting, other, blank (no answer) & Other & $7 \%$
\end{tabular}

$\mathrm{MOI}$ - maritime occupational injury; $\mathrm{CMOI}$ - circumstances of the $\mathrm{MOI}$

Table 5. Percentage of accidents for each macro category of accident type

\begin{tabular}{lll}
\hline CMOI types of accidents & Categories after grouping & Accidents [\%] \\
\hline Fall from own height & Fall from own height (A) & 11.64 \\
Hitting fixed obstacle & Hitting fixed obstacle (B) & 10.17 \\
Being struck, swept along, pinned & Being struck, swept along, pinned (C) & 26.78 \\
Being cut or pricked by & Being cut or pricked by (D) & 15.29 \\
Excess effort or awkward movement & Excess effort or awkward movement (E) & 18.56 \\
Falling from height, falling overboard, fire and explosion, & Other (F) & 17.52 \\
burn or frostbite, electric shock, diving accident, other & & \\
CMOI - circumstances of the maritime occupational injury & &
\end{tabular}

$\mathrm{CMOI}$ - circumstances of the maritime occupational injury

to the type of fishery. Offshore fishery is significantly associated with accidents occurring in bad weather conditions whereas it is the opposite for inshore fishery. In terms of fishing gears, there is a significant relationship between the use of trawl and the occurrence of occupational injuries in bad sailing conditions.

\section{Activity of the wounded fishermen at the time of the accident}

A previous study [13] led to group several modalities of the variable "fisherman's task". Table 4 shows this grouping, which reveals that two types of tasks are particularly dangerous: tasks related to the fishing gear on the one hand and tasks related to processing the catch on the other.

The distribution of injuries among these macro-categories of tasks presents the same main features as those observed in the former study, which showed that operations related to the fishing gear caused $51 \%$ of the injuries and that the proportion of injuries linked to catch processing represented $32 \%$ of all accidents recorded during the period 1996-2001.

In the present study, cross-referencing these macro-categories with the different types of fishery reveals significant links between:

- inshore fishery and accidents occurring during operations related to the fishing gear;

- high seas fishery and accidents occurring during "additional tasks".

Considering the type of gear used reveals the following results:
- a positive and significant relation between the use of nets and the occurrence of accidents during additional tasks;

- a negative and significant relation between the use of pots and the occurrence of accidents during additional tasks.

\section{Types of accidents}

Table 5 shows the main types of MOls. In order to compare the results of the present study to the results of the former one, the modalities that were less represented have been grouped together.

No significant link appears between the types of accidents and the types of fishery. In contrast, three significant relations appear when considering the type of gear used on board the vessels:

- accidents of the type "being struck, swept along, pinned" are underrepresented in the netting activity;

- these accidents are overrepresented in the dredging activity;

- accidents of the type "being cut or pricked by" are overrepresented in potting and lining activities.

A statistical analysis of the relationships existing between the tasks carried out by the wounded fisherman at the time of the accident and the type of accident was conducted. A comparison of the observed frequencies with the theoretical frequencies that would be obtained under the assumption of independence revealed that strong positive links exist between: 
Table 6. Percentage of accidents by categories of material elements

\begin{tabular}{lll}
\hline Material elements involved & Categories after grouping & Accidents [\%] \\
\hline Ship's movement, heavy seas & External conditions (A) & 15.78 \\
Fishing gear, otter board, warp, robe, cable, ..., hauling gear or winch & Fishing and hauling gears (B) & 36.17 \\
Fish processing gear/knife/fish or shell & Fish and fish processing devices (C) & 13.22 \\
Basket, box, container & Transport and storage devices (D) & 7.39 \\
Device in engine room/cart or trolley/conveyor or lift & Others (E) & 27.44
\end{tabular}

- fishing gear operations and accidents of the type "being struck, swept along, pinned";

- catch processing operations and accidents of the type "cuts";

- catch processing operations and accidents of the type "excess effort or awkward movement";

- additional tasks and "other types of accidents";

- other tasks and "other types of accidents".

\section{Material elements involved}

The fishing gear is the element that is the most frequently involved in maritime occupational injuries (23.63\%), followed by the "other" category, and then by the "ship's movement" (13.29\%). There is no statistically significant relation between the material elements involved and the type of fishery. In contrast, three strong significant relations appear when considering the fishing activity (type of gear used):

- accidents involving the otter board are overrepresented in trawling,

- accidents involving the fishing gear are overrepresented in dredging,

- accidents involving the catch are overrepresented in netting.

Table 6 shows the five categories left after grouping the less represented items.

Concerning the relationships existing between the material elements and the tasks of the wounded fishermen at the time of accidents, a comparison of the observed frequencies with the theoretical frequencies that would be obtained under the assumption of independence revealed that there are highly significant and positive links between:

- accidents occurring during catch processing operations and the material elements "fish and fish processing devices";

- accidents occurring during catch processing operations and the material elements "transport and storage devices";

- accidents occurring during operations related to the fishing gear and the material elements "fishing and hauling gears".

\section{Consequences of MOI}

The most frequent consequences of MOls are bruises and muscle strain (19.82\%), open wounds (17.99\%), fractures and dislocation (16.86\%), "other consequences" (15.04\%), and backache (13.22\%).

There is no significant relationship between one particular category of consequences and one type of fishery, whereas a significant link appears when considering the fishing activity. Open wounds are overrepresented in lining. Furthermore, a statistical analysis showed that strong significant relationships exist between the accident consequences and the activity of the wounded fishermen at the time of the accidents, namely between:

- fishing gear operations and fractures or dislocation;

- catch processing operations and backache;

- other tasks and "other consequences".

\section{Location of injuries}

The most frequent locations of injuries are the hands and fingers (29.25\%), thorax and abdomen (15.09\%), upper limbs (14.81\%), and lower limbs (14.8\%). Thus, the hands remain the part of the body that is the most often injured, as it has already been shown [9, 13-16].

No relationship may be observed between the injury location and the type of fishery. In contrast, a strong relationship appears when considering the fishing activity. Hand injuries are overrepresented in the lining activities.

\section{Discussion}

During the fishing operations, fishermen are faced with three main risks:

- R1 - the risk of "being hit by something", related to the fishing gear operations and involving the fishing gear; fishing gear operations are, themselves, correlated with fractures or dislocation. Several studies have already identified this risk as a major one, with regard to both the frequency and the seriousness of accidents [9, 13, 17].

- R2 - the risk of "cuts", related to catch processing and involving the fish and knives.

- R3 - the risk associated with manual handling (named "excess effort"), which is also linked to catch process- 
ing and involved transport and storage devices; catch processing is, itself, correlated with backache.

Relationships exist between these risks and the accidents related to them on the one hand and the fishing activity on the other hand:

- risk $\mathrm{R} 1$ - "being hit by", is overrepresented in dredging;

- risk R2 - "to be cut or pricked by", concerns mainly the passive gears, since cuts are overrepresented in netting and lining activities, as it has already been shown [18].

\section{DISCUSSION}

The present study focuses on the frequency and the nature of occupational injuries in the French sea fishing industry. Compared to the statistical studies that are carried out annually in France, its originality lies in the fact that it explores the link existing between occupational injuries and the fishing activity. Specifically for the Brittany region and for the year 2012, it shows a high incidence rate as well as substantial variations of the $\mathrm{MOI}$ incidence rate according to the type of fishery. The high number of $\mathrm{MOl}$ is not specific to the year 2012. It should be emphasized, furthermore, that this number is likely to be underestimated, because accidents are under-reported in the sea fishing industry.

The present study shows that MOls are more frequent in the offshore and coastal fishing industries than in the inshore or the high seas fisheries. Working and safety conditions are certainly better on board large fishing vessels because they are less cramped than smaller ones and, above all, because they belong to companies with a specific safety department. It may also be assumed that fatigue is less important in inshore fishery than in offshore or coastal fisheries, because small-scale vessels return to port every evening. Hence, they may also remain in port more often than the others when the weather conditions are bad. For a given type of fishery, there are, however, few differences according to the fishing activity of the vessels (using either passive or active gears), except for inshore fishery where the IR is far higher for active than for passive gear. When considering the main features of the MOls, the opposite statement can be made: they seem to be more dependent on the fishing activity than on the type of fishery.

The present study also had a methodological purpose. This purpose was to define reliable and objective indicators that could be used to characterise the occupational injuries in the fishing industry and to compare different fishing activities. This article has indicated the method used to calculate these elements. In order to take the exposure to danger into account, the number of accidents has been related to the FTE workforce rather than to the number of fishermen. In order to generalise this analysis, it would be necessary to establish a link between the vessel database and the social data. Such a link could be created using the vessel registration data that are included in both databases.

This study also provides information concerning the vessels' versatility in Brittany in 2012. There is no versatility in high seas fishery, and it is rare in offshore fishery. In both cases, the variables "type of vessel" and "fishing activity" are, therefore, conflated. Versatility is not negligible in coastal fishery, but it is limited to the use of several gears belonging to the same group (either passive gear or active gear). In contrast, versatility concerns most of the vessels in inshore fishery and is, furthermore, highly diversified.

These findings lead to the following recommendation: for the smallest vessels, investigations should be conducted and monographs produced to analyse occupational injuries that are specific to a specific flotilla of vessels (e.g., flotilla of scallop dredgers). Such monographs, restricted to a particular flotilla, should be produced in collaboration with the relevant healthcare services. They would highlight specific dangers and risks and different protection factors (technical, human, and organisational ones), like in the studies carried out in Andalusia for the artisanal fishery [18], in Portugal for the flotillas of longliners of Sesimbra and seiners of Peniche [19] or in Poland for coastal and beach fishing [20]. Such monographs could also help increase understanding of the reasons why occupational injuries are more frequent in the offshore and coastal fisheries than in other fisheries.

\section{CONCLUSIONS}

In conclusion, quantitative approaches to occupational injuries - such as those that have been presented in this article - can usefully reveal disparities in the distribution of accidents, according to geographical or functional factors [21]. However, more qualitative studies are required to provide greater insights regarding the root causes of these phenomena.

\section{ACKNOWLEDGEMENTS}

The authors are grateful to the Institut Maritime de Prévention (Maritime Institute for Prevention) and the Comité National des Pêches et des Elevages Marins (French National Committee of Maritime Fishing and Marine Fish Farming) that commissioned and supported this study.

\section{REFERENCES}

1. Jensen OCC, Petursdottir G, Holmen IM, et al. A review of fatal accident incidence rate trends in fishing. Int Marit Health. 2014; 65(2): 47-52, doi:10.5603/IMH.2014.0011, indexed in Pubmed: 25231324.

2. Jaremin B, Kotulak E. Mortality in the Polish small-scale fishing industry. Occupational Medicine. 2004; 54(4): 258-260, doi: 10.1093/ occmed/kqh054.

3. Chaumette P. De la prévention à la pêche maritime. Revue Française des Affaires Sociales 2008; 2-3: 323-339.

4. Laursen $\mathrm{LH}$, Hansen $\mathrm{HL}$, Jensen OC. Fatal occupational accidents in Danish fishing vessels 1989-2005. Int J Inj Contr Saf Promot. 
2008; 15(2): 109-117, doi: 10.1080/17457300802240503, indexed in Pubmed: 18642168.

5. Roberts SE. Britain's most hazardous occupation: commercial fishing. Accid Anal Prev. 2010; 42(1): 44-49, doi: 10.1016/j. aap.2009.06.031, indexed in Pubmed: 19887143.

6. McGuinness E, Aasjord H, Utne I, et al. Fatalities in the Norwegian fishing fleet 1990-2011. Safety Science. 2013; 57: 335-351, doi:10.1016/j.ssci.2013.03.009.

7. Aasjord HL. Tools for improving safety management in the Norwegian Fishing Fleet occupational accidents analysis period of 1998-2006. Int Marit Health. 2006; 57(1-4): 76-84, indexed in Pubmed: 17312696.

8. EUROSTAT. Statistiques européennes sur les accidents du travail (SEAT) - Résumé de la méthodologie. Methodologies \& Working papers 2012. EU .http://ec.europa.eu/eurostat/statistics-explained/ index.php/File:Fatal_accidents_at_work,_2011_and_2012_ ( $\left.{ }^{1}\right)$ (standardised_incidence_rates_per_100_000_persons_employed)_YB15-fr.png.

9. McGuinness $\mathrm{E}$, Aasjord $\mathrm{H}$, Utne I, et al. Injuries in the commercial fishing fleet of Norway 2000-2011. Safety Science. 2013; 57: 82-99, doi:10.1016/j.ssci.2013.01.008.

10. Observatoire prospectif des métiers et des qualifications de la pêche. L'emploi à la pêche en 2012. Note n²013/01 2013.http://www. spppcm.fr/bases/pdf/fichier-action/44/emploi2012vd.pdf.

11. Berciaud P, Colas C. Rapport sur les accidents du travail - Année 2009-2010 - Ministère de l'Ecologie, de l'Energie, du Développement durable et de la Mer. 2012 . http://www.developpement-durable. gouv.fr/IMG/pdf/rapport_d_accidents_de_travail_maritime-1_ cle62b7c7.pdf.

12. Le Bouar G, Chauvin C. An analysis of the risk in the French sea fishing industry. Example of the dockside accident risk. Int Marit Health. 2006; 57(1-4): 103-113, indexed in Pubmed: 17312699.
13. Chauvin C, Le Bouar G. Occupational injury in the French sea fishing industry: a comparative study between the 1980 s and today. Accid Anal Prev. 2007; 39(1): 79-85, doi: 10.1016/j.aap.2006.06.006, indexed in Pubmed: 16962060.

14. Matheson C, Morrison S, Murphy E, et al. The use of NHS accident and emergency services by commercial sea fishermen in the North East of Scotland. Occup Med (Lond). 2005; 55(2): 96-98, doi: 10.1093/occmed/kqi037, indexed in Pubmed: 15757982.

15. Kaustell KO, Mattila TEA, Rautiainen RH. Occupational injuries and diseases among commercial fishers in Finland 1996-2015. Int Marit Health. 2016; 67(3): 163-170, doi: 10.5603/IMH.2016.0031, indexed in Pubmed: 27681217.

16. Frantzeskou E, Jensen OC, Linos A. Health status and occupational risk factors in Greek small fisheries workers. Int Marit Health. 2016; 67(3): 137-143, doi: 10.5603/IMH.2016.0026, indexed in Pubmed: 27681212

17. Törner M, Nordling PO. Occupational injury in Swedish fishery: Analysis of injury statistics. Occupational Ergonomics 1999. 2000; 2: 81-89.

18. Piniella F, Soriguer MC, Walliser J. Analysis of the specific risks in the different artisanal fishing methods in Andalusia, Spain. Safety Science. 2008; 46(8): 1184-1195, doi: 10.1016/j.ssci.2007.08.006.

19. Antão P, Almeida T, Jacinto C, et al. Causes of occupational accidents in the fishing sector in Portugal. Safety Science. 2008; 46(6): 885-899, doi:10.1016/j.ssci.2007.11.007.

20. Jeżewska M, Grubman-Nowak M, Leszczyńska I, et al. Occupational hazards for fishermen in the workplace in Polish coastal and beach fishing: a point of view. Int Marit Health. 2012; 63(1): 40-48, indexed in Pubmed: 22669811.

21. Perez-Labajos C, Azofra M, Blanco B, et al. Analysis of accident inequality of the Spanish fishing fleet. Accid Anal Prev. 2006; 38(6): 1168-1175, doi:10.1016/j.aap.2006.05.007, indexed in Pubmed: 16797464. 